\title{
Common Spaces in Nomadic Housing: Two Types of Intended Use in Turin City Centre
}

\author{
Simona Canepa \\ Department of Architecture and Design, Politecnico di Torino, Torino 10125, Italy
}

\begin{abstract}
New nomadism is a movement of global intensification that configures ways of living, inhabiting, and being in the world. The case studies of the temporary residences in Turin, in areas characterized by problems of urban decay and social tensions with a high rate of immigration, are both a technical and social experimental intervention aiming, through the recovery of the existing degraded property, to transform it into a new living model of social housing, from which it will benefit not only the residents but also the entire urban area. The concept of the spaces has profoundly changed. It is no longer tied to the domestic and work sphere only, it now includes all places of associated and collective life.
\end{abstract}

Key words: Building and social renovation, temporary housing, common spaces.

\section{Introduction}

Turin, like many Italian cities, has been known in the last years for immigration phenomena from different countries, Morocco, Tunisia, Romania, China, India, Philippines, Peru, Senegal and Nigeria, that have significantly changed the neighborhoods where immigrants have settled.

This high rate of immigration has requested and required the development of significant social cohesion policies. Coexistence between different populations has been and is still partly a source of tension, but also helped to create a multicultural environment, creative and rich in terms of stories, traditions and attractive spaces.

In these areas, the housing problem is severe: if before the phenomenon was related to the poverty of the population and the presence of immigrants, the housing problems of recent years include young couples, mono-nuclear families with children, extended families, elders, city users and students. The cause is to be found mainly in the economic crisis to which it will be added the aging population, social

\footnotetext{
Corresponding author: Simona Canepa, researcher, research field: interiors and exhibit. E-mail: simona.canepa@polito.it.
}

changes and job insecurity.

The answer to this question is the social housing as the set of housing and communal services between the tenants [1].

\section{The Users of Temporary Residences}

"Common places" is the name chosen to designate the projects of Porta Palazzo Temporary Residence in Piazza della Repubblica (Fig. 1) and San Salvario Temporary Residence in Via San Pio V in Turin (Fig. 2): a name that represents the spirit of the initiative by the Housing Programme in collaboration with the Compagnia di San Paolo [2]. The adjective common is referred to the apartments because those who live in these units know that it is not forever and every room, every piece of furniture, every furnishings, will soon be used by other people; common means also that in and out of the apartments there are spaces where tenants can meet, learn, talk and exchange experiences.

The temporary residences are a proposal of social nature, with the intent to contribute the emergence of a new housing culture. They are intended for people that need a living arrangement in a short time and for a maximum of 18 months but not only, users may be 


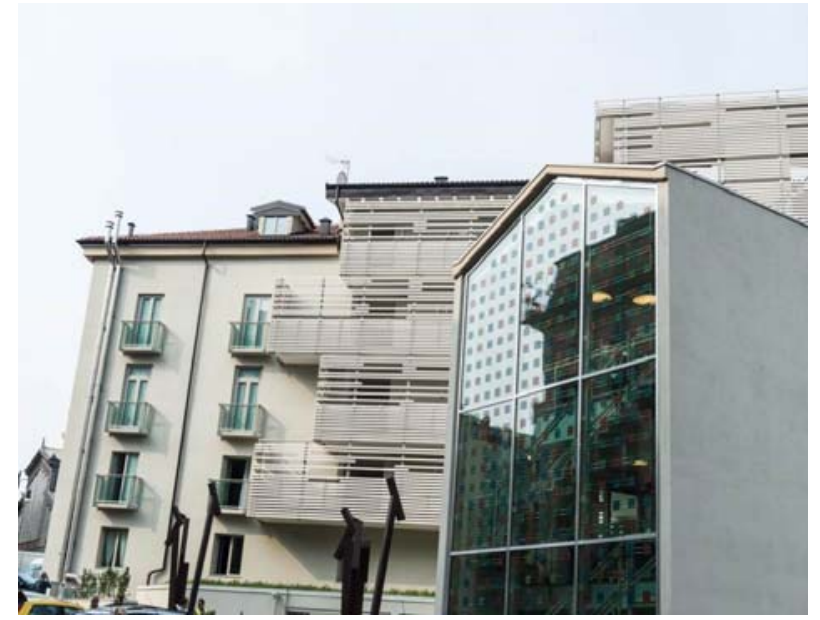

Fig. 1 Porta Palazzo Temporary Residence.

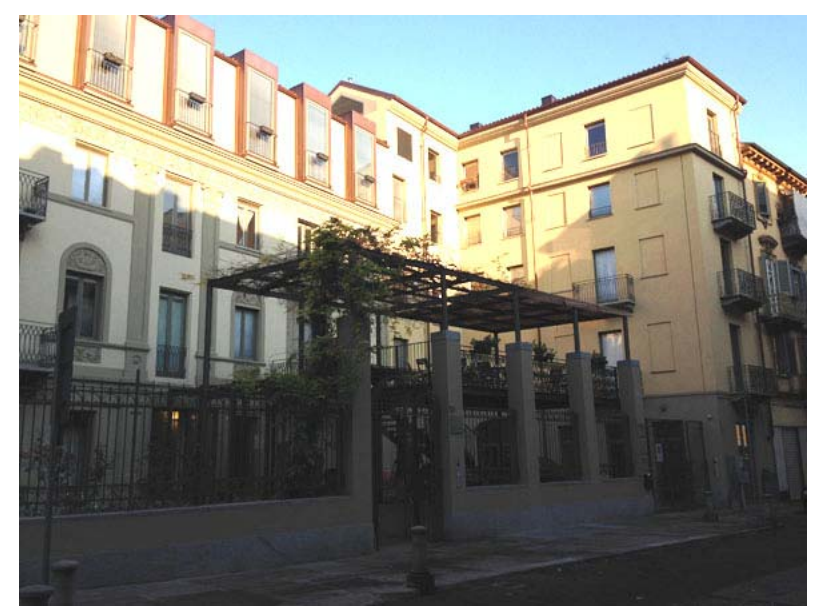

Fig. 2 San Salvario Temporary Residence.

represented by students, interns, who need an apartment to rent for a period of time, waiting to be able to settle permanently, for people who travel to Turin to visit or use services, trainees, workers and professionals from outside the city.

The big difference between the two residences is that the one in Porta Palazzo, opened in 2013, is for singles or couples without children (it has 27 units divided into 14 apartments and 13 studios), the one in San Salvario, opened two years later, is for couples and families with children (it has 5 studios, 8 apartments, 10 two bedroom units and 1 three bedroom unit, so it is possible to accommodate a minimum of 1 person to a maximum of 6 persons).

The active involvement of those living in the temporary residences is very important: it is intended to be a home for those who stay, even for short periods, enhancing mutual understanding and exchange, involving the people in the care of common areas and in the organization of different activities.

\section{The Choice of the Urban Areas}

The municipality of Turin has identified in the centre two areas where social tensions are high, and in these areas two run-down buildings to launch a challenge to the housing needs of those who live a phase of transition and therefore economic and social vulnerability.

The choice of existing buildings with architectural features to be protected, instead of new construction outside the city centre, has been an urban-type social intervention against the degradation-that too often debases metropolitan areas-and social intervention on people (Fig. 3).

Porta Palazzo, where the first temporary residence is settled, derives its name from the ancient Roman gate in the north-west access of the city, in the context of the original Roman castrum Julia Augusta Taurinorum in 28 A.D. about. Piazza della Repubblica, the real heart of the neighborhood, was renovated by the Duke Vittorio Amedeo II in the early 18th century with the construction of baroque buildings with porches. Between 1825 and 1830, the current octagonal shape of the square was designed and a daily market, the biggest in Europe, has taken place since 1835 [3]: the square is the meeting place of cultures and folklore with its variety of products, colors and smells.

San Salvario is a 19th-century building district, which derives its name from a small church of 1646 (and its convent), commissioned by Madama Cristina, wife of King Victor Amadeus I of Savoy, who wanted a place of worship near the summer residence of the Valentino Castle along the river. The demolition of the Turin city walls in 1840 created the basis for the actual development of the village, when the neighborhood began to be populated by a new bourgeoisie [3]. Currently, the district hosts many cultural, craft activities 


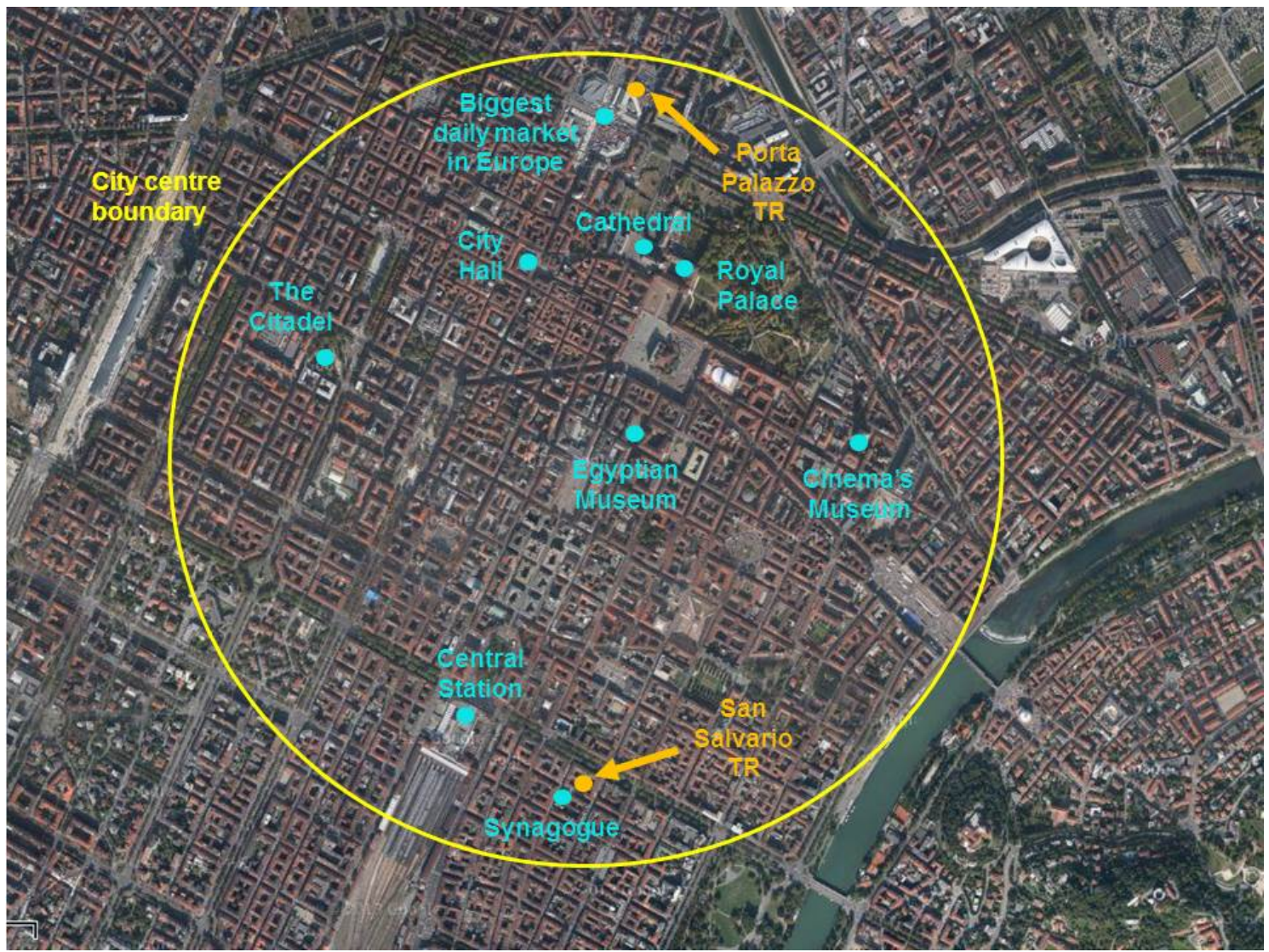

Fig. 3 Floor plan of Turin city centre with the highlight of the temporary residences.

and service sector in general, with a vibrant nightlife.

\section{Public and Private Common Spaces}

S. Chermayeff and C. Alexander in their "Relationship space and private space" [4] claim that the house should be considered part of the urban anatomy, and they identify a public and a private sphere one linked to the other through a hierarchical sequence of spaces: it is about gradual or abrupt changes from an eminently public situation, typical of the collective places of the city, to the private sphere of the individual housing. These steps are realized through hallways and meeting spaces between public ownership and private property, between the collective behavior and private and family one (Fig. 4).

Many experiences of cohabitation teach that, in order to develop a relationship of solidarity and collaboration within a condominium, common spaces that respond to concrete and daily necessities of the people are necessary and that should constitute a point of meeting and sharing.

\subsection{Porta Palazzo Temporary Residence}

The complex consists of a historic building of four floors on the front towards Piazza della Repubblica, bound with regard to the facade on the square, and two underground floors of cellars; on the side facing Via Priocca in a later building perpendicular to the main one, consisting of three floors above ground and a basement; in an outdoor courtyard open on the street.

The proposed redevelopment of the winning group Fagnoni and Associati Architetti from Florence, has provided for the building of Piazza della Repubblica commercial units on the ground floor and housing units in the remaining three floors above ground and in the attic; for the building on the front of Via Priocca, a restaurant arranged over three levels and the manager's office; for the courtyard, arrangement and furnishing of 


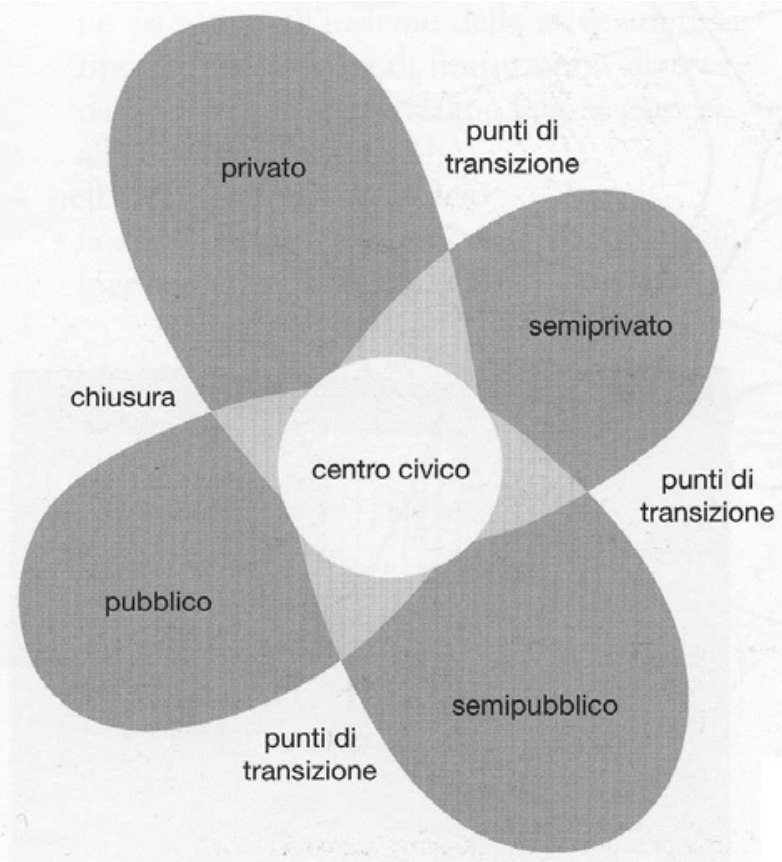

Fig. 4 Different types of spaces.

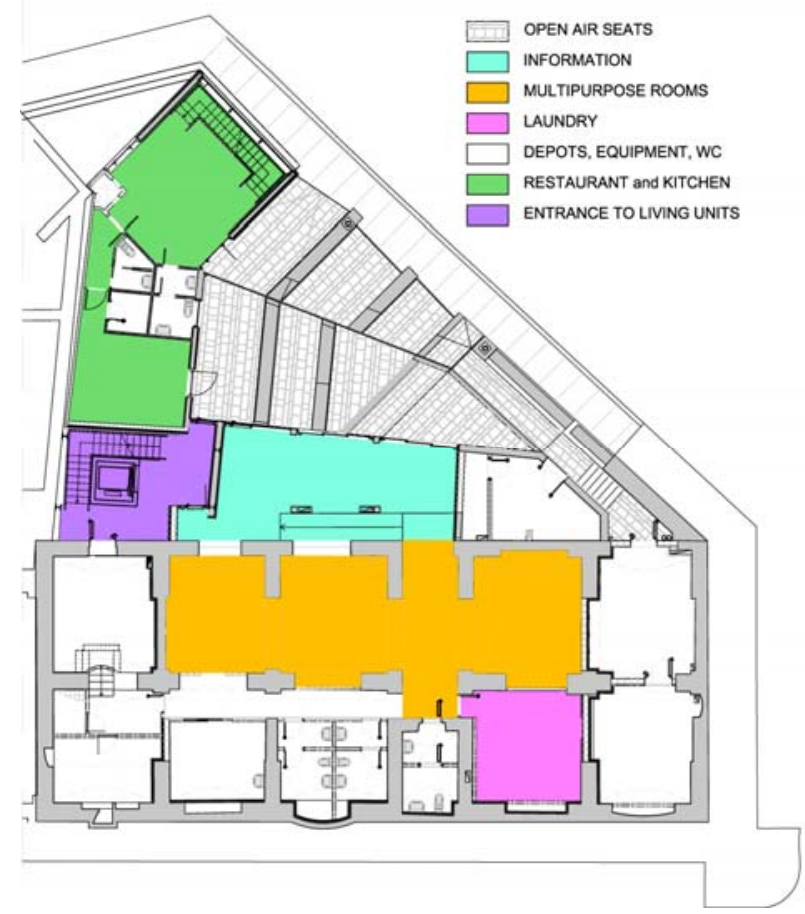

Fig. 5 Ground floor plan of Porta Palazzo T.R.

the open spaces towards the city and the construction of inner service areas for temporary residence (Fig. 5).

The new square represents a filter space between the house and the road, but at the same time an integration space between "internal” and "external". The courtyard has terraces and stone seats that could accommodate in the new square all those looking for a place to stop and have a rest (Fig. 6).

The main entrance leads directly to a disengagement zone which distributes to the stairwell and elevator. Alongside a separate entrance leads to the new core which abuts the main building and overlooks the courtyard. This new space $\left(80 \mathrm{~m}^{2}\right)$ has large windows that look out on the courtyard garden space and is a space where the information services of the residence is concentrated (Fig. 7).

This communicates, through a series of arches on the existing historic façade (reopened during renovation) with what was once the wine cellar of the property. The perceived space is represented by the new core from a wide portion of basement. The basement is used in part

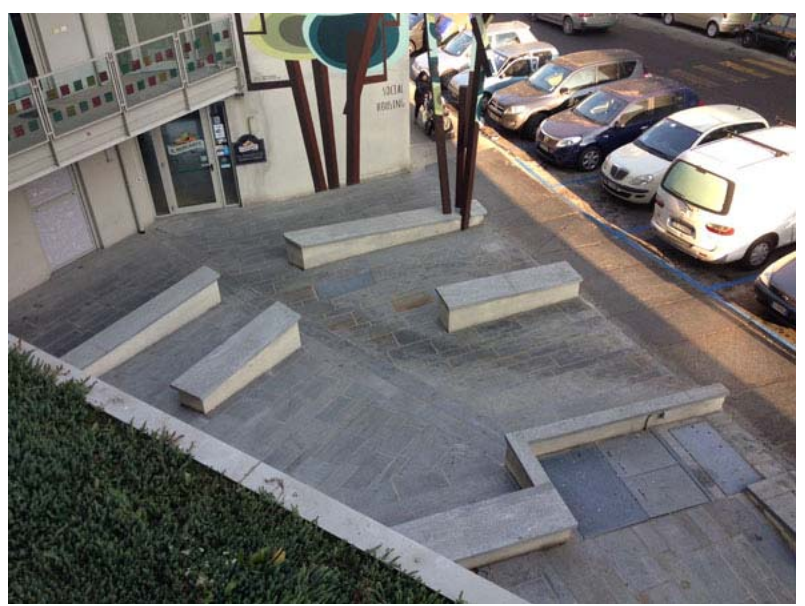

Fig. 6 Public common spaces in front of the main entrance.

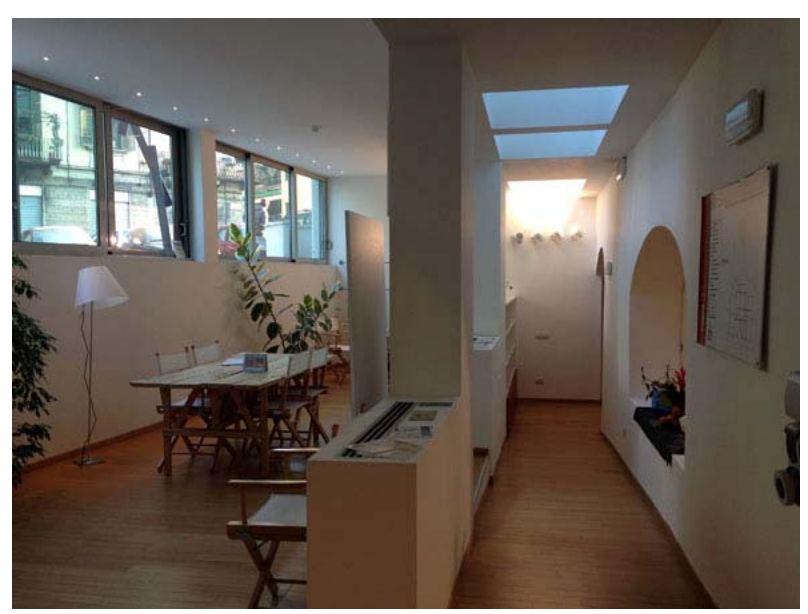

Fig. 7 The entrance to the multipurpose space. 
to create a multipurpose space $\left(200 \mathrm{~m}^{2}\right)$ divided into three large rooms open and interconnected, in which different activities can be made such as a projection room, a small library, a public meeting room and an entertainment area for residents during afternoon and evening (Figs. 8 and 9).

The inside leads instead to the laundry and ironing room for the use of the residence.

On the opposite side of the large communal living room are the places for technical equipment and storage.

The gallery distribution can also be considered common space. The choice of this distribution, compatible with the morphology of the building, was to obtain the maximum number of apartments but also create areas outside the apartments where tenants can meet and chat together (Fig. 10).

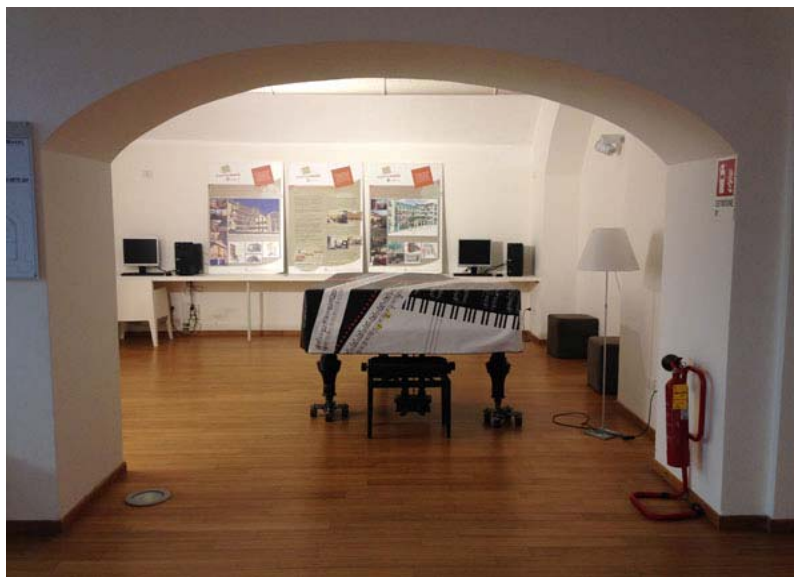

Fig. 8 Multipurpose space used as internet room and music room.

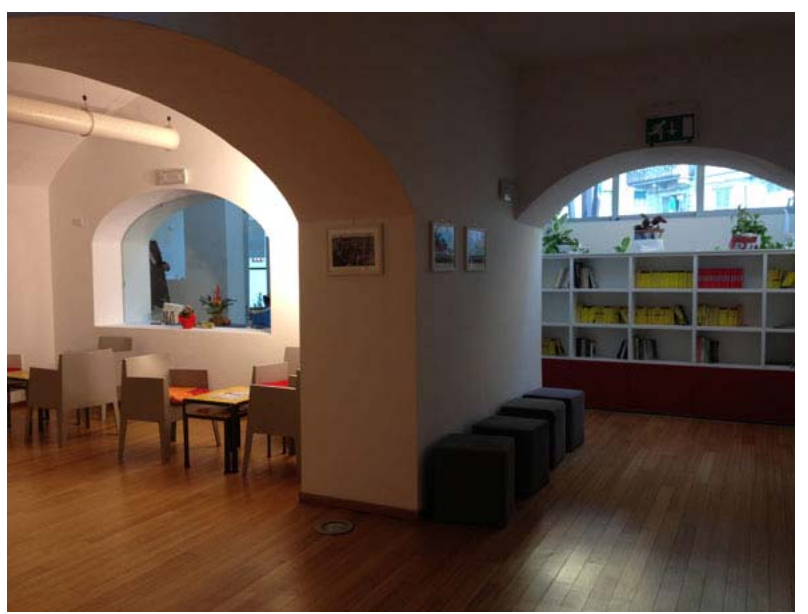

Fig. 9 Multipurpose space used as living room and as small library.

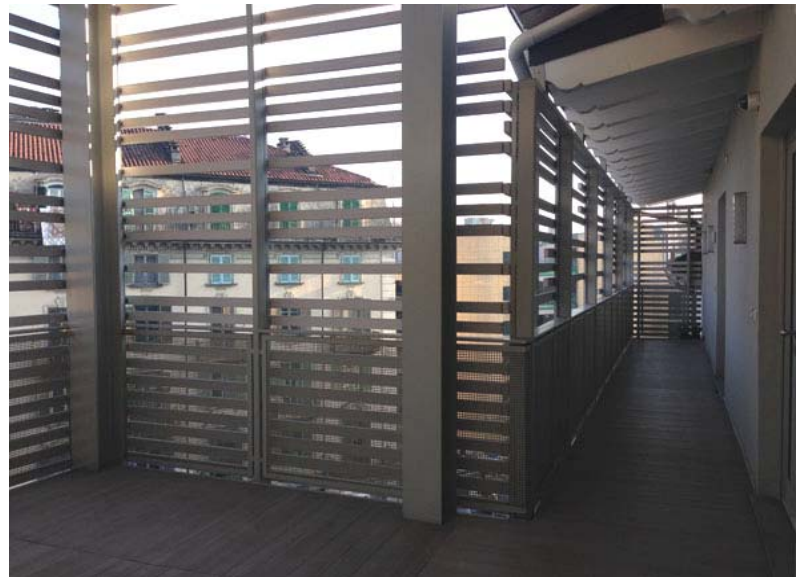

Fig. 10 Distribution corridor to the living units.

\subsection{San Salvario Temporary Residence}

The building is a complex of great architectural interest built in 1862, used as a kindergarten, girls' orphanage and school for girls. The complex consisted of four wings constructed around a central courtyard, plus two smaller wings projecting at the sides of the main building on Via San Pio V and a low building backs onto the main façade. The proposed redevelopment of the winning group Studio De Ferrari Architetti from Turin has provided to demolish the low building improving in this way the architectural image of the main façade on the street. The renovation project includes the temporary residence, a nursery school, the residence and the chapel for Santa Maria Institute nuns, owner of the complex, and some activities open to the public, such as commercial activities and cultural activities linked to the neighborhood (Fig. 11).

At the entrance of the complex, there is a beautiful common garden fully recovered (Fig. 12): the centennial wisteria has been preserved with a new light support structure within a common terrace for tenants was built. It can be used also as open air space by people using the cafeteria.

The inner courtyard is a common space for the nursery school but could be used also for recreational and educational purposes: a self-cleaning window and coverage of the courtyard has been realized, two large voids accommodate existing trees that can be seen by the galleries connecting the housing units (Fig. 13). 


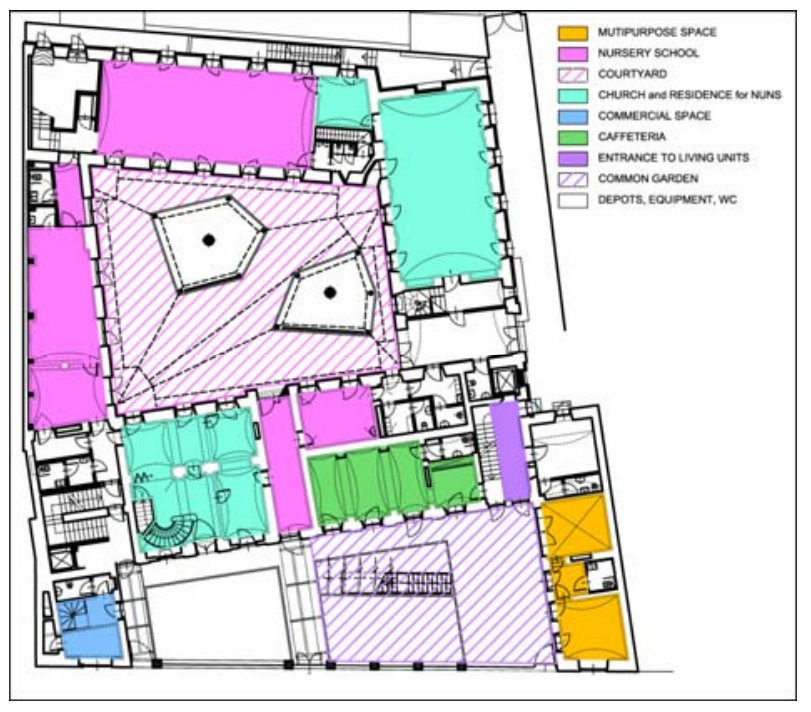

Fig. 11 Ground floor plan of San Salvario T. R.

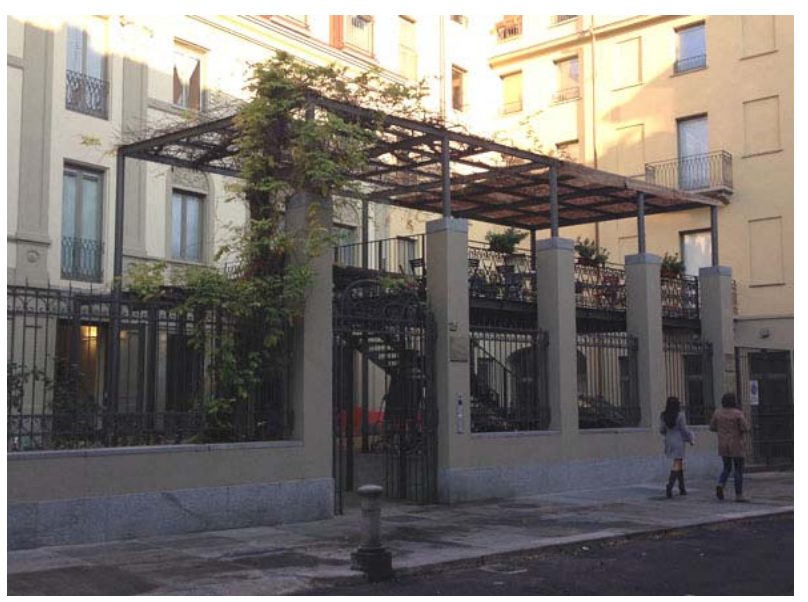

Fig. 12 The centennial wisteria on the common terrace.

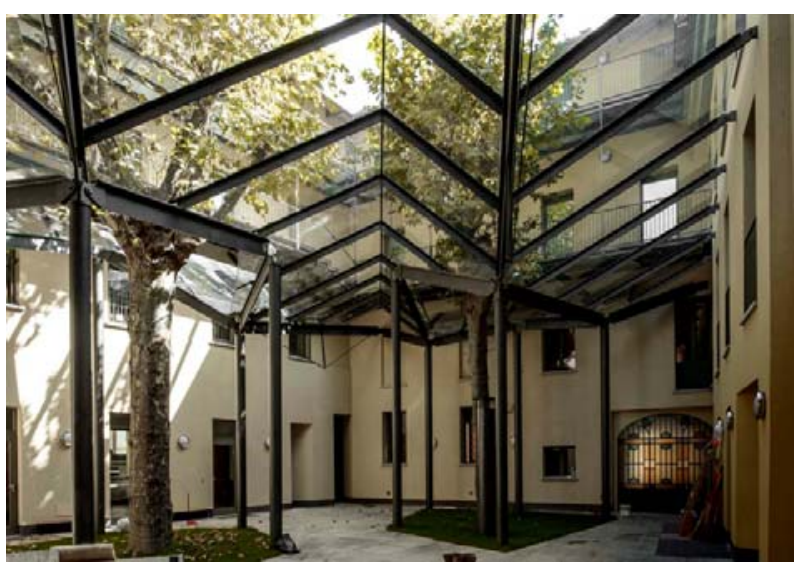

Fig. 13 The inner courtyard for the nursery school (photo by Studio De Ferrari Architetti).

The public space, located on the ground floor in the right wing, is intended for the dialogue and the integration of the structure with the neighborhood and the territory within which organizing activities is aimed at residents but also to all the inhabitants of district; multifunctional and accessible activities both through initiatives organized either by the operators or by the tenants, or directly by citizens who request them (Fig. 14).

The temporary residence offers a common area for shared use by the tenants on the fourth floor. This common area is set up for different functions that affect the daily life of the residents, with the aim of facilitating the reconciliation of the times, the enhancement of skills and the solution of small problems of the everyday life.

So it is a meeting place for social occasions, space in which organizing collective services between tenants (for example, the day meal preparation to facilitate the reconciliation of the families present in the residence) (Figs. 15 and 16).

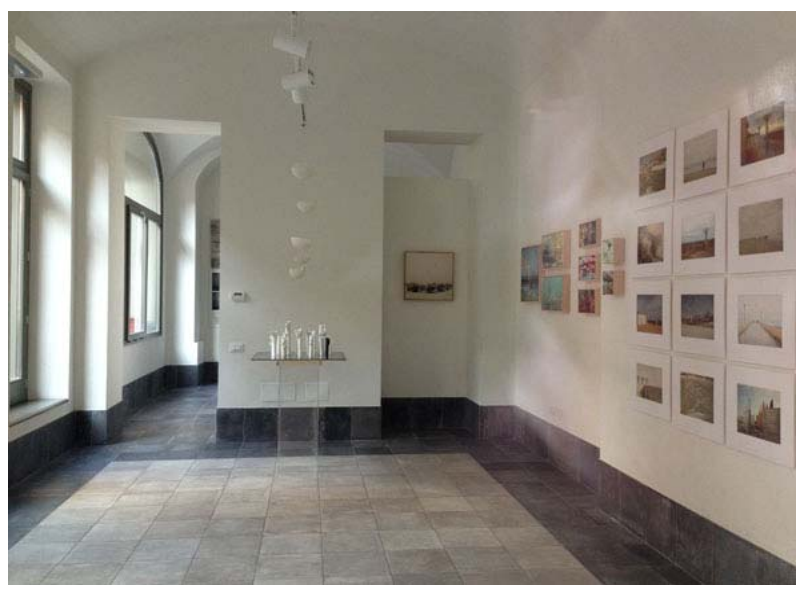

Fig. 14 Public space on the ground floor during a temporary exhibition.

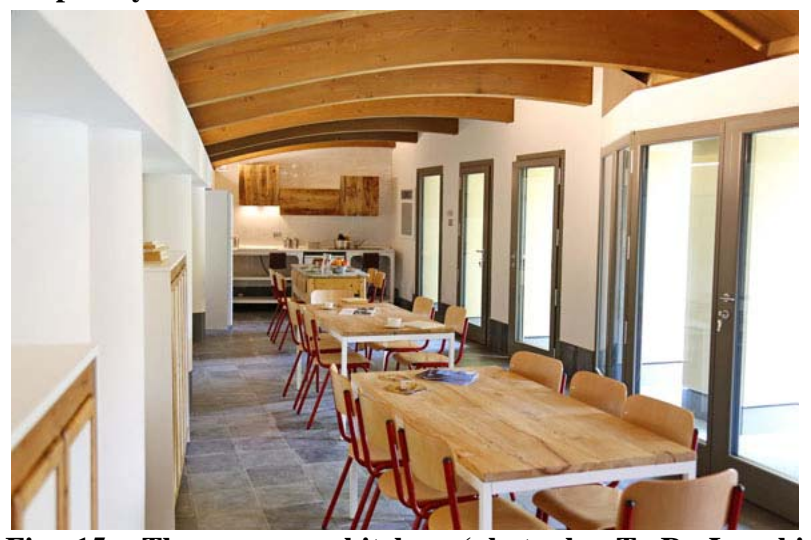

Fig. 15 The common kitchen (photo by T. R. Luoghi Comuni San Salvario). 


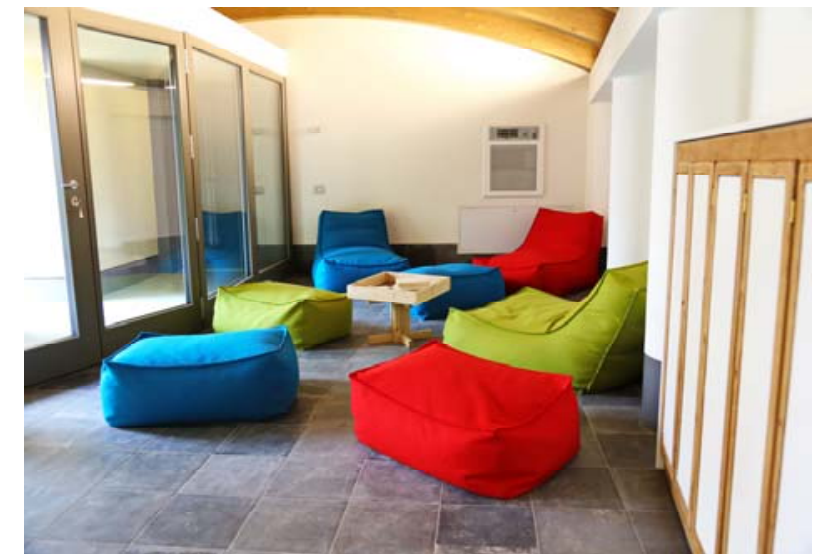

Fig. 16 Part of the common kitchen area used as living room (photo by T. R. Luoghi Comuni San Salvario).

It can be used for birthday parties, for good neighborly dinners and for a collective babysitting of the residents; to propose the laboratories of the doing like cooking and DIY (do it yourself), to exchange skills and expertise and experience models that combine the needs of children and those of adults. It's a simple, comfortable, familiar space which can be separated from the kitchen with movable walls.

\section{Conclusions}

Building and social renovation, temporary residence, sustainable intervention, common, public and private spaces: these are some of the key words that have guided the refurbishment of the temporary residences, made with the aim to improve the urban and social centre of a shattered city area. The operation has returned to the city and the neighborhood a renovated building in its exterior appearance and interior spaces, able to provide an answer to the growing housing needs expressed by the population that is placed in the so-called "gray band", to whom belong people who have no access to public housing but, at the same time, cannot compete on their own in the free market, and also an environment in which they can feel active part in the social life that derives from it, so as to avoid that housing vulnerability situations become uncomfortable and even social exclusion. In these temporary residences, people with different economic and cultural background can meet and, thanks to their diversity, are capable of generating forms of cohabitation in which everyone can benefit [5].

\section{References}

[1] Pittini, A. 2012. “L’Edilizia Sociale ai Tempi Della Crisi.” Journal of Technology for Architecture and Environment 04/2012 . (in Italian)

[2] Ingaramo, L., ed. 2015. Social Housing Modelli $e$ Processi per Valutare la Sostenibilità. Torino: Celid. (in Italian)

[3] Comoli Mandracci, V. 1989. Le Città Nella Storia di'Italia. Roma-Bari: Laterza Editori. (in Italian)

[4] Vaudetti, M., and Canepa, S. 2010. Architettura Degli Interni e Progetto Dell'Abitazione. Torino: Utet Scienze e Tecniche. (in Italian)

[5] Capelli, E. 2015. "Il Social Housing come Politica Pubblica.” Giornale on-line di Urbanistica, Jan.-Mar. 2015. (in Italian) 